
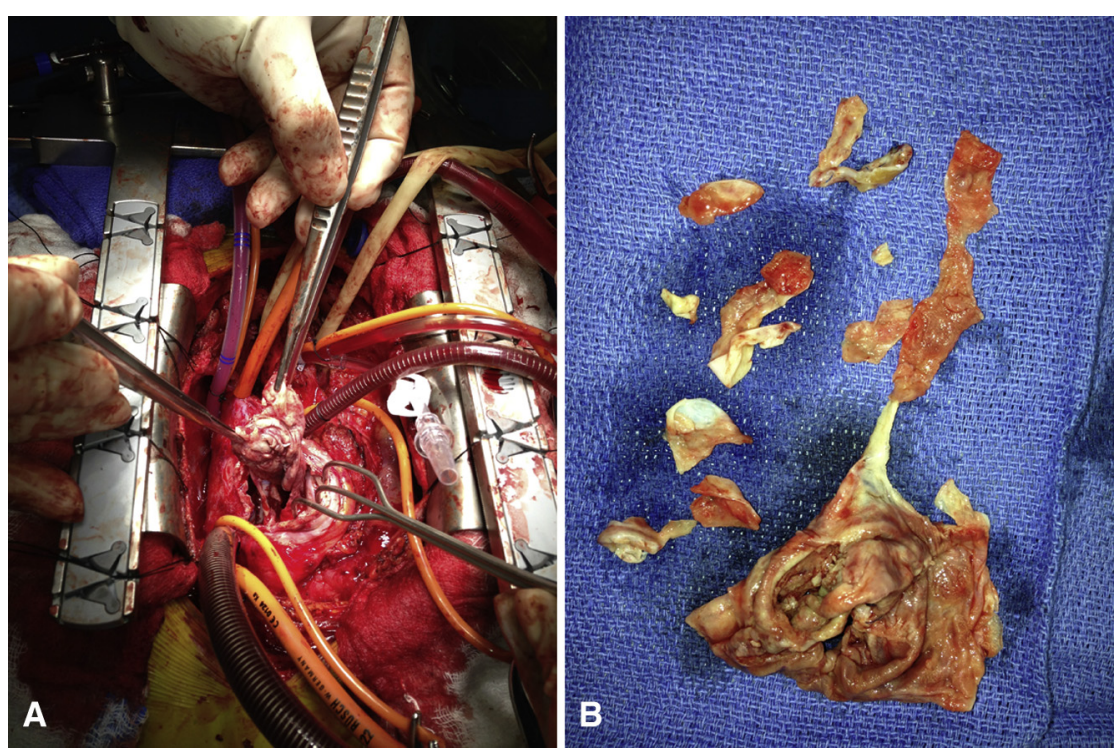

FIGURE 4. Intraoperative photographs of the CorMatrix extracellular matrix tube at removal. A, Prolapsing CorMatrix tube. B, Resected CorMatrix tube showing infection and degenerative changes.

continuity is preserved. ${ }^{4}$ The failure that we observed in this case may have been due to the weak antiinfective property of CorMatrix or to its fragile nature when it is in the body for certain duration. CorMatrix ECM's resistance to infection depends on angiogenesis and thus on the patient's own defense mechanisms. This may not be adequate.

In conclusion, reconstruction of the entire tricuspid valve with the ECM tube technique is efficacious in achieving excellent valve function. The CorMatrix ECM, however, may not be the ideal material to provide long-term durable outcomes.

\section{References}

1. Fallon AM, Goodchild TT, Cox JL, Matheny RG. In vivo remodeling potential of a novel bioprosthetic tricuspid valve in an ovine model. J Thorac Cardiovasc Surg. December 19, 2013 [Epub ahead of print].

2. Mumtaz S, Pretorius V, Madani M, Jamieson SW. CorMatrix fashioned tricuspid valve as alternative to valve resection for acute infective endocarditis. Presented at: The 93rd Annual Meeting of the American Association for Thoracic Surgery; May 4-8, 2013; Minneapolis, MN

3. Sündermann SH, Rodriguez Cetina Biefer H, Emmert MY, Falk V. Use of extracellular matrix materials in patients with endocarditis. Thorac Cardiovasc Surg. 2014;62:76-9.

4. Okita Y, Miki S, Kusuhara K, Ueda Y, Tahata T, Yamanaka K, Higa T. Analysis of left ventricular motion after mitral valve replacement with a technique of preservation of all chordae tendineae. Comparison with conventional mitral valve replacement or mitral valve repair. J Thorac Cardiovasc Surg. 1992;104:786-95.

\title{
Retroesophageal total anomalous pulmonary venous connection in a neonate
}

Lindsay A. Caldarone, ${ }^{\mathrm{a}}$ Christopher A. Caldarone, $\mathrm{MD},{ }^{\mathrm{b}}$ and Luca A. Vricella, $\mathrm{MD},{ }^{\mathrm{a}}$ Baltimore, Md, and Toronto, Ontario, Canada

\footnotetext{
From the Division of Cardiac Surgery, ${ }^{a}$ Johns Hopkins University School of Medicine, Baltimore, Md; and The Hospital for Sick Children, ${ }^{b}$ University of Toronto, Toronto, Ontario, Canada.

Disclosures: Authors have nothing to disclose with regard to commercial support.

Received for publication April 8, 2014; accepted for publication April 11, 2014; available ahead of print June 13, 2014.

Address for reprints: Luca A. Vricella, MD, Director, Pediatric Cardiac Surgery and Heart Transplantation, Johns Hopkins University, 1800 Orleans St, Zayed 7107G,

Baltimore, MD 21287 (E-mail: lvricella@jhmi.edu).

J Thorac Cardiovasc Surg 2014;148:e143-5

0022-5223/\$36.00

Copyright (c) 2014 by The American Association for Thoracic Surgery

http://dx.doi.org/10.1016/j.jtcvs.2014.04.022
}

In 1957, Darling and colleagues ${ }^{1}$ proposed a classification scheme for total anomalous pulmonary venous connection (TAPVC). According to this scheme, only $5 \%$ of patients have "unusual" morphology, including mixed (type IV) or nonconfluent veins. We present to our knowledge the first reported case of retroesophageal pulmonary venous confluence.

\section{CASE REPORT}

A 2-month-old, 4.3-kg term infant with no previous cardiac diagnosis was found cyanotic and listless and was 
transported emergently to our institution, where a transthoracic echocardiogram revealed nonobstructed supracardiac TAPVC with a vertical vein coursing posterior to the left pulmonary artery and draining into the left brachiocephalic vein. The patient was brought to the operating room with the expectation that routine repair of supracardiac TAPVC would be performed.

During surgery, however, the pulmonary venous confluence could not be located through the posterior pericardium. After cardioplegic circulatory arrest was induced with profound hypothermia, we attempted localization of the confluence and proceeded to go as far as transecting the inferior vena cava in the hope of finding the confluence once the heart could be fully mobilized and the posterior retrocardiac mediastinum completely exposed. The left and right pulmonary veins could be identified in the respective pulmonary hila; when they were followed and carefully dissected, however, they were noticed to be coursing posterior to the esophagus (Figure 1, A). The esophagus was mobilized in its mid portion, exposing the retroesophageal confluence; the reconstruction was then undertaken by vertically transecting the pulmonary venous confluence, yielding 2 pulmonary venous ostia measuring approximately 5 to $6 \mathrm{~mm}$ in diameter. Each half of the divided confluence was incised on its anterior aspect, and spatulated anastomoses were constructed. The left venous confluence was anastomosed directly onto the left atrial appendage with a 7-0 running polypropylene suture (modified Warden procedure); the right atrium was incised transversely across the interatrial septum and onto the posterior left atrial wall. The right venous confluence was anastomosed to the posterior transverse atriotomy (Figure 1,B), and the atrial septal defect was closed with a patch of autologous pericardium. The postoperative course was uneventful, and the infant was discharged home on the 10th postoperative day. The child is alive and well with no residual pulmonary venous obstruction 3 years after the initial operation.

\section{DISCUSSION}

The near totality of cases of TAPVC can be accounted for within the classification scheme proposed in 1957 by Darling and colleagues. ${ }^{1}$ According to this anatomic classification, only $5 \%$ of patients present with "unusual" morphology, including mixed (type IV) or nonconfluent veins. Several unusual patterns have been described ${ }^{2,3}$; to our knowledge, however, no case of retroesophageal pulmonary venous confluence has thus far been reported. In mixed types without obstruction or with complex associated cardiac anomalies, it might be beneficial to delineate further the anatomy with diagnostic imaging to aid in operative planning. In the case reported here, the patient had the condition correctly diagnosed as nonobstructed supracardiac TAPVC, although the confluence's relationship

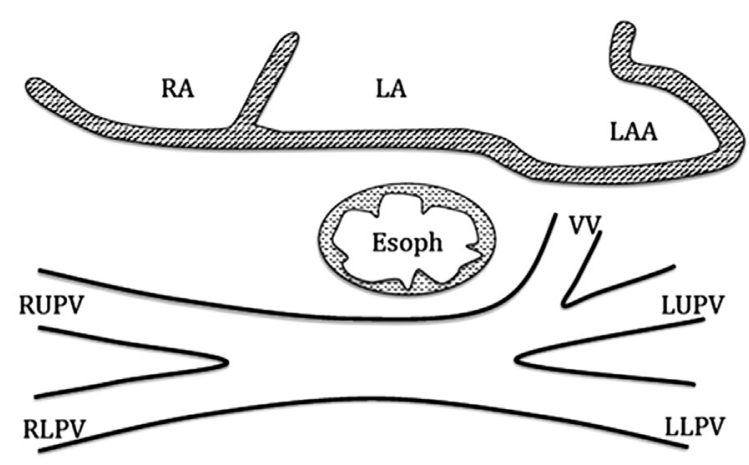

A

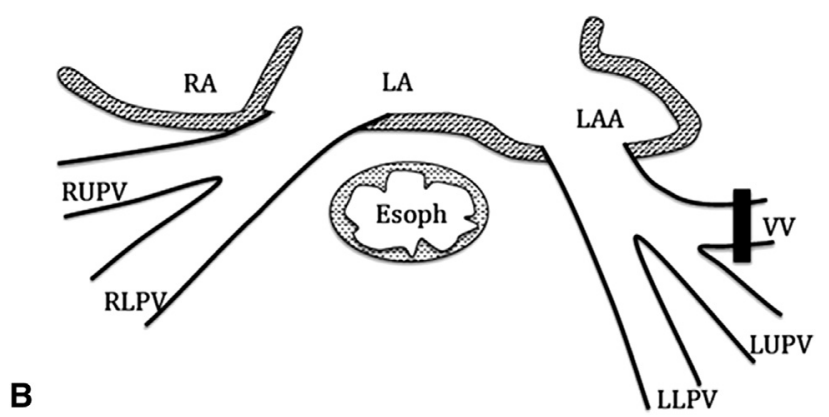

FIGURE 1. A, Schematic, axial rendition of retroesophageal total anomalous pulmonary venous connection. B, Schematic of situation after vertical transection of the retroesophageal confluence. The right veins are anastomosed to the posterior wall of the left atrium and the left veins to the left atrial appendage. $R A$, Right atrium; $L A$, left atrium; $L A A$, left atrial appendage; Esoph, esophagus; $V V$, vertical vein; $R U P V$, right upper pulmonary vein; $L U P V$, left upper pulmonary vein; $R L P V$, right lower pulmonary vein; $L L P V$, left lower pulmonary vein.

with the esophagus could not be accurately delineated by preoperative transthoracic echocardiography.

Intraoperatively, even transection of the inferior vena cava did not aid in elucidating the anatomy, and only antegrade dissection of the veins from the respective hila was able to disclose the site of the obstruction behind the esophagus. Once the venous pattern was identified as joining behind the esophagus, two options were feasible to obtain unobstructed pulmonary venous return. The first would have been to perform a "sutureless repair" by incising the veins and the overlying parietal pericardium. ${ }^{4}$

The dissection around the esophagus had by this decision point been too extensive, leaving little pericardial integrity around the veins to allow for a hemostatic repair. We chose instead to anastomose the respective confluences individually to the left atrial appendage and to the posterior wall of the left atrium. Because of the size of the vessels and the goal of minimizing the potential for late stenosis, we spatulated the anastomoses to maximize their linear length. 


\section{References}

1. Craig JM, Darling RC, Rothney WB. Total pulmonary venous drainage into the right side of the heart; report of 17 autopsied cases not associated with other major cardiovascular anomalies. Lab Invest. 1957;6:44-64.

2. Bharati S, Lev M. Total anomalous pulmonary venous drainage. In: Bharati S, Lev M, eds. The pathology of congenital heart disease: a personal experience with more than 6,300 congenitally malformed hearts. Armonk (NY): Futura Publishing; 1996. 609-26.
3. Cameron D. Repair of unusual types of total anomalous pulmonary veins. Oper Tech Thorac Cardiovasc Surg. 2001;6:50-7.

4. Yun TJ, Coles JG, Konstantinov I, Al-Radi OO, Wald RM, Guerra V, et al Conventional and sutureless techniques for management of the pulmonary veins: evolution of indications from postrepair pulmonary vein stenosis to primary pulmonary vein anomalies. J Thorac Cardiovasc Surg. 2005;129: $167-74$.

\title{
A novel hybrid technique for transcatheter pulmonary valve implantation within a dilated native right ventricular outflow tract
}

\author{
Frances C. Travelli, MD, ${ }^{\mathrm{a}}$ Cynthia S. Herrington, MD, ${ }^{\mathrm{b}}$ and Frank F. Ing, MD, ${ }^{\mathrm{a}}$ Los Angeles, Calif
}

Since the Food and Drug Administration approval of the Melody transcatheter pulmonary valve (Medtronic Inc, Minneapolis, Minn) in 2010, multiple reports of its use to treat dysfunctional right ventricle-to-pulmonary artery conduits have been published. ${ }^{1,2}$ However, use of this valve is limited to 16- to 22-mm diameter conduits or bioprosthetic valves. ${ }^{1}$ The Melody valve is not recommended for native right ventricular outflow tracts (RVOTs) because of its general dilated anatomy and high compliance of the native tissue, rendering a high risk of device malposition or embolization. We report a novel hybrid technique of Melody valve implantation within a dilated native RVOT.

\section{CLINICAL SUMMARY}

A 17-year-old male patient with tetralogy of Fallot status post-transannular patch repair at age 1 month presented with severe pulmonary insufficiency and increasing exercise intolerance. Cardiac magnetic resonance imaging showed a markedly dilated right ventricle, right ventricular indexed end-diastolic volume $194 \mathrm{~mL} / \mathrm{m}^{2}$, regurgitant fraction $50 \%$, and preserved biventricular function. The dilated native RVOT diameter was $24 \mathrm{~mm}$. Because of mild developmental delay resulting from a cerebral infarct after his initial tetralogy of Fallot repair, the decision was made to

\footnotetext{
From the Divisions of Cardiology, Departments of Pediatrics ${ }^{\mathrm{a}}$ and Cardiothoracic

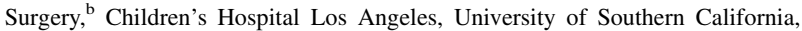
Los Angeles, Calif.

Disclosures: Cynthia S. Herrington and Frank F. Ing report consulting fees from St. Jude Medical. All other authors have nothing to disclose with regard to commercial support.

Received for publication March 7, 2014; revisions received April 17, 2014; accepted for publication April 24, 2014; available ahead of print June 11, 2014.

Address for reprints: Frank F. Ing, MD, Children's Hospital Los Angeles, 4650 Sunset Blvd, MS\#34, Los Angeles, CA 90027 (E-mail: fing@ chla.usc.edu).

J Thorac Cardiovasc Surg 2014;148:e145-6

$0022-5223 / \$ 36.00$

Copyright (c) 2014 by The American Association for Thoracic Surgery

http://dx.doi.org/10.1016/j.jtcvs.2014.04.046
}

avoid the risks of cardiopulmonary bypass and proceed with the hybrid approach for Melody valve implantation.

After a midline sternotomy and exposure of the RVOT, a $12 \mathrm{~mm}$ in width short "tube" was cut from a 22-mm polytetrafluoroethylene graft (Gore-Tex, WL Gore \& Associates Inc, Flagstaff, Ariz). This tube was then cut and wrapped around the main pulmonary artery (MPA) just above the pulmonary annulus to "restrict" the MPA diameter to 22 mm (Figure 1). The width and location of the tube were carefully selected by dissecting the MPA from the aorta and measuring the distance from the pulmonary annulus to the take-off of the right pulmonary artery. The coronary

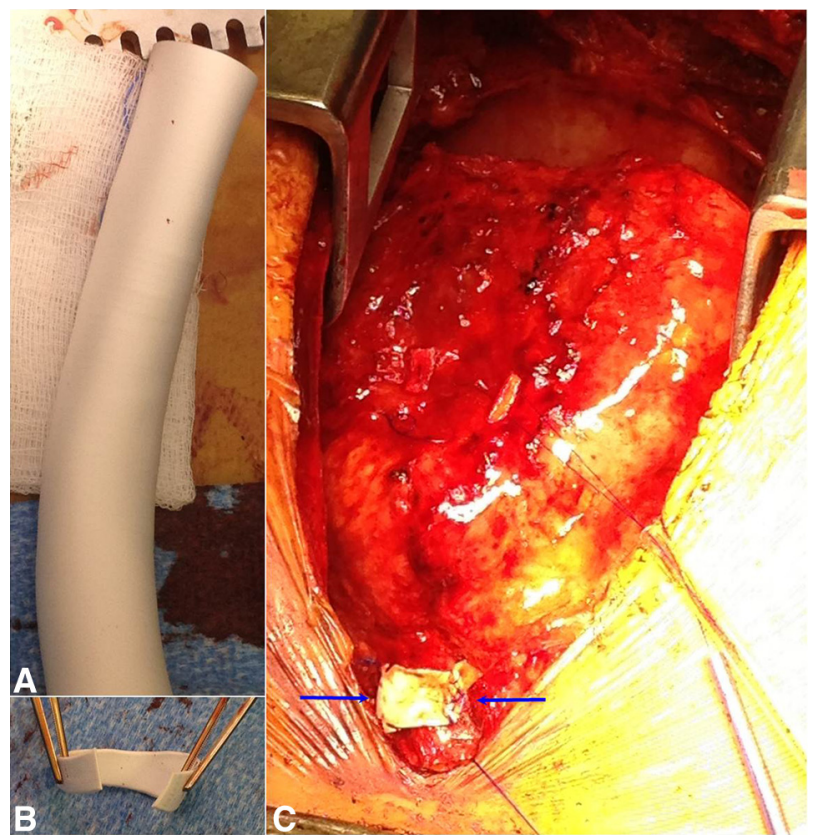

FIGURE 1. A, A 22-mm polytetrafluoroethylene tube. B, A 12-mm width short tube cut and opened. $\mathrm{C}$, The tube is placed around the RVOT (blue arrows) to be used as the landing zone for the Melody valve (Medtronic Inc, Minneapolis, Minn). 